\title{
Ciliated cell variant of endometroid carcinoma in bilateral ovaries: A rare variant
}

\author{
${ }^{1}$ M. Rajani, ${ }^{2}$ G. Sailabala, ${ }^{3}$ C. Padmavathi devi, ${ }^{4}$ M. Koteswari \\ ${ }_{1,2,3,4}$ Department of Pathology, Guntur Medical College, Guntur, Andhra Pradesh, India
}

\begin{abstract}
Endometrial Carcinoma of Ovary accounts for $10-20 \%$ of ovarian malignancy. Ciliated cell variant of endometrial carcinoma is very rare. We reported a case of bilateral endometroid carcinoma of ovaryciliated cell variant in a 50 yrs old female without any evidence of tumor in endometrium.
\end{abstract}

Key words: Ciliated, Endometroid carcinoma, Bilateral Ovaries

\section{Introduction} endometriosis ${ }^{(1)}$

Ciliated cell variant of endometroid carcinoma of ovary is very rare. It is usually associated with

\section{Case Report}

A 52 yrs female presented with abdominal distension dyspnea since 2 months. Attained menopause 5 years ago. On examination vague abdominal mass of about 18 x $20 \mathrm{cms}$ with variable consistency, restricted mobility with ascites seen. Ultrasound abdomen revealed large heterogeneous lesion extending from umbilicus to pelvis measuring $25 \times 15 \mathrm{~cm}$. The patient underwent bilateral salpingo oophorectomy and the specimen was sent for histopathological examination.

\section{Morphology}

Grossly received two ovarian masses with tubes and omental mass. Larger mass of size 16 × 8 x $7 \mathrm{cms}$, external surface was nodular. (Figure 1). Cut section showed predominantly solid with focal cystic areas which showed papillary excrescences. (Figure2)

The smaller mass of size $9 \times 6 \times 4 \mathrm{cms}$. External surface was nodular with cysts and papillary excrescences. Its cut section predominantly was solid with focal cystic areas and papillary excrescences. Both tubes and omentum were normal.

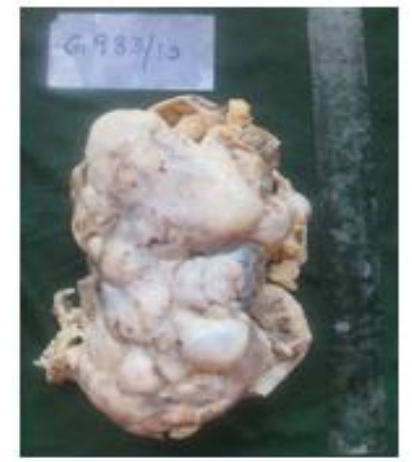

Figure1: larger mass with nodular and cystic surface

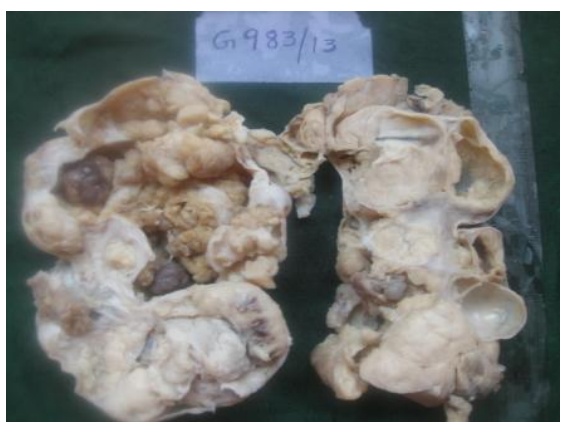

Figure 2: cut section predominantly solid with cystic areas 


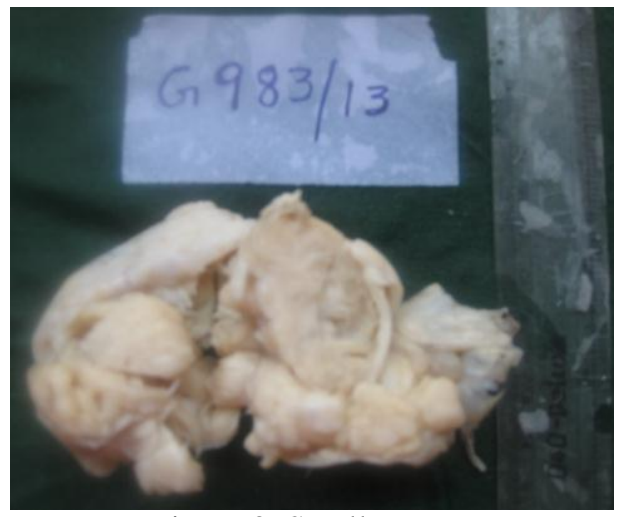

Figure 3: Smaller mass

Microscopic examination from both the ovarian masses showed proliferation of glands lined by tall stratified ciliated columnar epithelium. The tumor cells are seen in cribriform (Fig 4), papillary (Fig 5), micro glandular (Fig 6) and focal villoglandular growth patterns. There were focal areas of necrosis and hemorrhage.

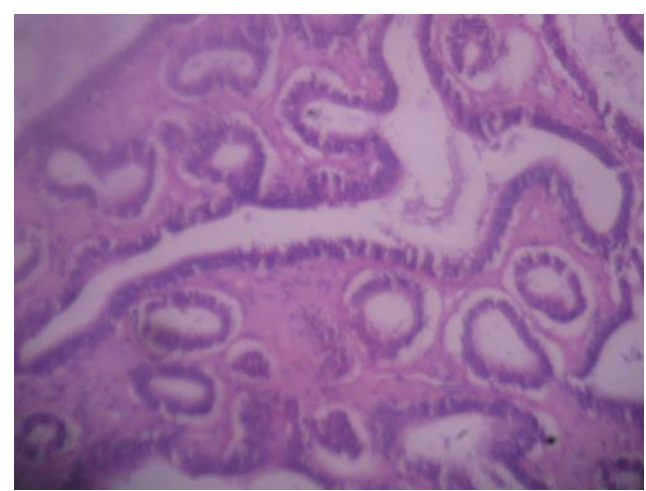

Figure4: 100x H \& E stained cribriform pattern with cilia

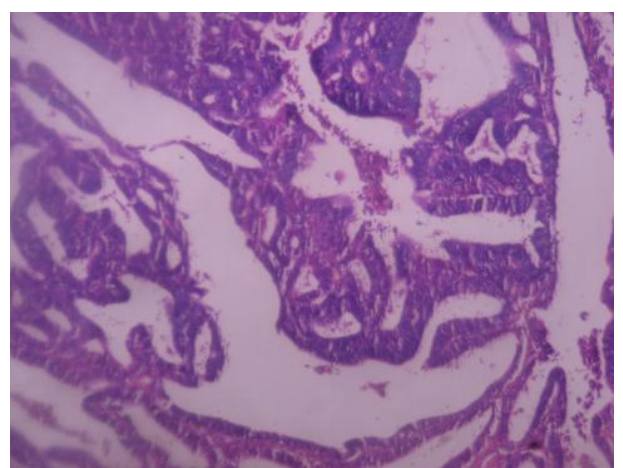

Figure 5: 100X H \& E papillary pattern

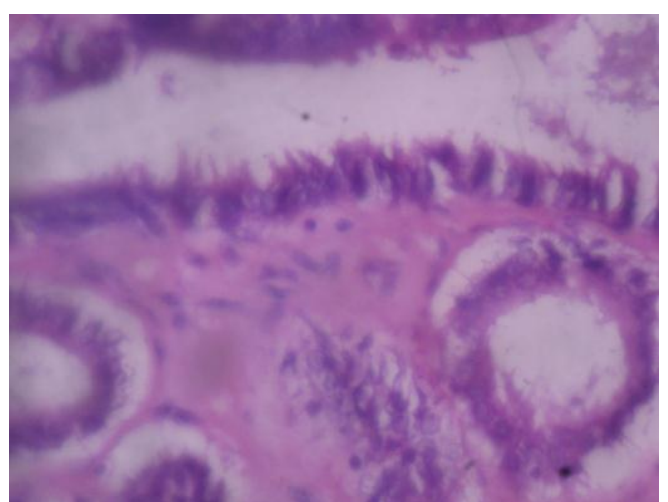

Figure 6: 100X H \& E microglandular pattern with cilia 


\section{Discussion}

Ciliated cell variant of endometroid carcinoma is a rare variant ${ }^{(1,2)}$ It is well differentiated and consists of glands lined predominantly by ciliated cells with abundant eosinophilic cytoplasm. At least $75 \%$ of tumor cells have to be ciliated for the tumor to be termed as ciliated cell carcinoma ${ }^{(3)}$. Cribriforming of the neoplastic glands is the characteristic architectural criteria of the subtype ${ }^{(2)}$. Cytologically cells show minimal nuclear atypia with mildly irregular nuclear contour and prominent nucleoli ${ }^{(4)}$. In this case it is bilateral. Predominantly cribriform pattern is seen, also seen are papillary, microglandular and villoglandular patterns lined by tall stratified ciliated columnar epithelium. It was not associated with endometrosis. Sections from endometrium show only proliferative phase.

\section{Conclusion}

This is a low grade rare variant of Ciliated cell endometroid carcinoma presenting in bilateral ovaries without associated endometriosis. There is a need for study of more of such cases of these histological variants to predict or assess prognosis. Clinical outcome and course of such rare cases is yet to be established. Very little literature is available regarding these atypical presentation and rare histological pattern.

\section{References}

[1]. Rosai \& Ackerman`s surgical pathology $10^{\text {th }}$ edition volume $2, \mathrm{Pg}-1570$

[2]. S.G.Silverberg, R.J.Kurman. F nogales, G.L.Muttur, Rakubile-Huds, F.A.Tavassoli, Tumors of uterine corpus. Fatteneh, A,. Tavassoli, Peter Pevilee. Pathology and genetics of tumors of breast and female genital organs. $4^{\text {th }}$ edition IARC press Lyon2003,218-229.

[3]. S.E.Low and A Nicol ciliated variant of endometrioid adenocarinoma J Clin Pathol 2004 December 57 (12) 1341 - 1342

[4]. John H. Eichhorn, MD and Robert E.Scully MD. Int J.Gynecol Pathol 1996 Jul 15 (3) 248-56.

[5]. Fanning J.Evans MC Peters A J etal. Endometroid adenocarcinoma histologic subtypes - Clinical and pathologic profile- Gynecol oncol 2:288-291, 1989 